Tropical Journal of Pharmaceutical Research, June 2009; 8 (3): 275-287

(C) Pharmacotherapy Group, Faculty of Pharmacy, University of Benin,

Benin City, 300001 Nigeria.

All rights reserved.

Review Article

Available online at http://www.tjpr.org

\title{
Nanotechnology and Drug Delivery Part 2: Nanostructures for Drug Delivery
}

\author{
Nelson A Ochekpe ${ }^{1 *}$, Patrick O Olorunfemi ${ }^{2}$ and Ndidi C \\ Ngwuluka ${ }^{2}$ \\ ${ }^{1}$ Department of Pharmaceutical Chemistry and ${ }^{2}$ Department of Pharmaceutics and Pharmaceutical Technology, \\ Faculty of Pharmaceutical Sciences, University of Jos, PMB 2084, Jos, Nigeria
}

\begin{abstract}
This is the second part of a review on nanotechnology in general and particularly as it pertains to drug deliver. In the earlier paper (Part 1), nanotechnology in nature, its history as well as design and methods were discussed. Its applications, benefits and risks were also outlined. In this paper (Part 2), various nanostructures employed in drug delivery, their methods of fabrication and challenges of nano drug delivery are reviewed. Nanotechnology is one approach to overcome challenges of conventional drug delivery systems based on the development and fabrication of nanostructures. Some challenges associated with the technology as it relates to drug effectiveness, toxicity, stability, pharmacokinetics and drug regulatory control are discussed in this review. Clearly, nanotechnology is a welcome development that is set to transform drug delivery and drug supply chain management, if optimally developed.
\end{abstract}

Keywords: Nanotechnology, Nanobiotechnology, Drug delivery, Nanostructures, Nanomaterials, Nanocarriers. 


\section{INTRODUCTION}

Nanotechnology by manipulation of characteristics of materials such as polymers and fabrication of nanostructures is able to provide superior drug delivery systems for better management and treatment of diseases. The nanostructures employed as drug delivery systems have multiple advantages which make them superior to conventional delivery systems. In Part I, the advantages of nanostructures in drug delivery were outlined.

These benefits account for the extensive research that have been undertaken into the development of nanostructures such as liposomes, nanocapsules, nanoemulsions, solid lipid nanoparticles, dendrimers, polymeric nanoparticles, etc, for delivery of drugs. The materials employed in the fabrication of nanostructures determine the type of nanostructures obtained and these nanostructures, in turn, determine the different properties obtained and the release characteristics of incorporated drugs.

\section{MATERIALS AND TYPES OF NANOSTRUCTURES}

\section{Polymeric nanoparticles}

Polymeric nanoparticles are colloidal solid particles with a size range of 10 to $1000 \mathrm{~nm}^{1}$ and they can be spherical, branched or shell structures. The first fabrication of nanoparticles was about 35 years ago as carriers for vaccines and cancer chemotherapeutics $^{2}$. They are developed from non-biodegradable and biodegradable polymers. Their small sizes enable them to penetrate capillaries and to be taken up by cells, thereby increasing the accumulation of drugs at target sites. Drugs are incorporated into nanoparticles by dissolution, entrapment, adsorption, attachment or by encapsulation, and the nanoparticles provide sustained release of the drugs for longer periods, e.g., days and weeks ${ }^{3}$. Nanoparticles enhance immunization by prevention of degradation of the vaccine and increased uptake by immune cells ${ }^{4}$. One of the determinants of the extent of uptake by immune cells is the type of polymer employed. In a study ${ }^{4}$ comparing poly-( $\varepsilon$-caprolactone) (PCL), poly (lactide-coglycolide) (PLGA) and their blend, PCL nanoparticles were the most efficiently taken up by immune cells due to their hydrophobicity. However, all polymeric nanoparticles elicited vaccine (diphtheria toxoid) specific serum IgG antibody response significantly higher than free diphtheria toxoid.

To target drugs to site of action, the drug can be conjugated to a tissue or cell specific ligand or coupled to macromolecules that reach the target organs. To target an anticancer agent to the liver, polymeric conjugate nanoparticles which comprised biotin and diamine-terminated poly (ethylene glycol) with a galactose moiety from lactobionic acid were prepared ${ }^{5}$.

Some other applications of nanoparticles include possible recognition of vascular endothelial dysfunction ${ }^{6}$; oral delivery of insulin $^{7}$; brain drug targeting for neurodegenerative disorders such as Alzheimer's disease ${ }^{8}$; topical administration to enhance penetration and distribution in and across the skin barrier ${ }^{9}$; and $\mathrm{pH}$-sensitive nanoparticles to improve oral bioavailability of drugs such as cyclosporine A ${ }^{10}$. Some polymers used in the fabrication of nanoparticles include chitosan, alginate, albumin, gelatin, polyacrylates, polycaprolactones, poly(D, L-lactide-co-glycolide) and poly (D, L-lactide) However, there are concerns about polymeric nanoparticles including cytotoxicity of by-products (although some, such as polyanhydrides, degrade into products that are biocompatible) and scalability.

\section{Liposomes}

Liposomes were first developed about 40 years $\mathrm{ago}^{2}$. They are small artificial vesicles (50 - 100nm) developed from phospholipids 
such as phosphatidylcholine, phosphatidylglycerol, phosphatidylethanolamine and phosphatidylserine, which have been used in biology, biochemistry, medicine, food and cosmetics $^{11-14}$. The characteristics of liposomes are determined by the choice of lipid, their composition, method of preparation, size and surface charge 1. Liposomes have been applied as drug carriers due to their ability to prevent degradation of drugs, reduce side effects and target drugs to site of action ${ }^{15}$. However, limitations of liposomes include low encapsulation efficiency, rapid leakage of water-soluble drug in the presence of blood components and poor storage stability ${ }^{15,16}$. However, surface modification may confer stability and structure integrity against harsh bio-environment after oral or parenteral administration ${ }^{17}$. Surface modification can be achieved by attaching polymers such as poly (methacrylic acid-co-stearyl methacrylate) and polyethylene glycol units to improve the circulation time of liposomes in the blood; and by conjugation to antibodies or ligands such as lectins for target specific drug delivery and stability $^{16-18}$

Applications of liposomes include transdermal drug delivery to enhance skin permeation of drugs with high molecular weight and poor water solubility ${ }^{19}$; a carrier for delivery of drugs, such as gentamicin, in order to reduce toxicity ${ }^{20}$; possible drug delivery to the lungs by nebulisation ${ }^{21}$; ocular drug delivery ${ }^{22}$ and in the treatment of parasitic infections. However, solid lipid nanoparticles (SLNs) provide an effective alternative due to their stability, ease of scalability and commercialisability ${ }^{23}$.

Other vesicular structures include transferosomes, ethosomes, niosomes and marinosomes which are used mainly for transdermal delivery ${ }^{11,24,25}$. Transferosomes are developed by incorporation of surfactant molecules (edge activators) such as sodium chlorate into liposomes while ethosomes are liposomes that are high in ethanol (up to $45 \%)$. Niosomes are vesicles developed from non-ionic surfactants and marinosomes are liposomes produced from a natural marine lipid extract containing a high poly (unsaturated) fatty acid (PUFA) ratio.

\section{Dendrimers}

Dendrimers are nanostructures produced from macromolecules such as polyamidoamine (PAMAM), polypropyleneimine and polyaryl ether; and are highly branched with an inner core. The particle size range is between 1 to $100 \mathrm{~nm}$ although their sizes are mostly less than $10 \mathrm{~nm}$. About 20 years ago, dendrimer studies centred on their synthesis, physical and chemical properties while exploration of their biological applications was initiated about thirteen years $\mathrm{ago}^{26}$. The uniqueness of dendrimers is based on their series of branches, multivalency, well defined molecular weight and globular structure with controlled surface functionality, which enhances their potential as carriers for drug delivery ${ }^{26,27}$. Their globular structures and the presence of internal cavities enable drugs to be encapsulated within the macromolecule interior. Dendrimers have been reported to provide controlled release from the inner core $^{27}$. However, drugs are incorporated both in the interior as well as attached on the surface. Due to their versatility, both hydrophilic and hydrophobic drugs can be incorporated into dendrimers.

Controlled multivalency of dendrimers enables attachment of several drug molecules, targeting groups and solubilising groups onto the surfaces of the dendrimers in a well defined manner ${ }^{26}$. Dendrimers are employed due to their size (less than 10nm), ease of preparation, functionality and their ability to display multiple copies of surface groups for biological recognition process ${ }^{28}$.

Water soluble dendrimers can bind and solubilise small molecules and can be used as coating agents to protect drugs and deliver to specific sites. Other applications of dendrimers include catalysis, gene and DNA delivery, biomimetics and as solution phase 
supports for combinatorial chemistry ${ }^{29}$. Some of the drug delivery applications include therapeutic and diagnostic utilization for cancer treatment ${ }^{30}$; enhancement of drug solubility and permeability (dendrimer-drug

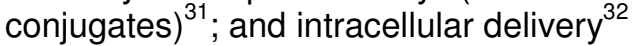

\section{Solid lipid nanocarriers}

Solid lipid nanoparticles (SLN) are nanostructures made from solid lipids such as glyceryl behenate (Compritol), stearic triglyceride (tristearin), cetyl palmitate and glycerol tripalmitate (tripalmitin) with a size range of 50 and $1000 \mathrm{~nm}^{33,34}$. Research interest in SLN emerged about ten years ago due to their scalability potential. The lipids employed are well tolerated by the body; large scale production will be cost effective and simple by using high pressure homogenization. Some of the features of SLN include good tolerability, site-specific targeting, stability (stabilized by surfactants or polymers), controlled drug release and protection of liable drugs from degradation ${ }^{34}$. However, SLN are known for insufficient drug loading, drug expulsion after polymorphic transition on storage and relative high water content of the dispersions ${ }^{34}$. SLN has been studied and developed for parenteral, dermal, ocular, oral, pulmonary and rectal routes of administration $^{34-39}$

To overcome the limitations of SLN, nanostructured lipid carriers (NLC) were introduced. NLC is composed of solid lipids and a certain amount of liquid lipids with improved drug loading and increased stability on storage thereby reducing drug expulsion ${ }^{34,36}$. NLCs have been explored for dermal delivery in cosmetics and dermatological preparations ${ }^{34,36}$.

Lipid drug conjugate (LDC) nanoparticles were introduced to overcome the limitation of types of drugs incorporated in the solid lipid matrix. Lipophilic drugs are usually incorporated in SLN but due to partitioning effects during production, only highly potent hydrophilic drugs effective in low concentrations are incorporated in $\mathrm{SLN}^{34}$. LDC enables the incorporation of both hydrophilic (e.g., doxorubicin and tobramycin) and lipophilic (e.g., progesterone and cyclosporine A) drugs ${ }^{34}$.

\section{Polymeric micelles}

Micelles are formed when amphiphilic surfactant or polymeric molecules spontaneously associate in aqueous medium to form core-shell structures or vesicles. Polymeric micelles are formed from amphiphilic block copolymers, such as poly(ethylene oxide)-poly( $\beta$-benzyl-Laspartate) and poly( $\mathrm{N}$-isopropylacrylamide)polystyrene, and are more stable than surfactant micelles in physiological solutions $^{39}$. They were first proposed as drug carriers about 24 years ago ${ }^{39}$. The inner core of a micelle is hydrophobic which is surrounded by a shell of hydrophilic polymers such as poly (ethylene glycol) ${ }^{40}$. Their hydrophobic core enables incorporation of poorly water soluble and amphiphilic drugs while their hydrophilic shell and size $(<$ $100 \mathrm{~nm}$ ) prolong their circulation time in the blood and increase accumulation in tumoural tissues $^{39}$.

Polymeric micelles are able to reach parts of the body that are poorly accessible to liposomes; accumulate more than free drugs in tumoural tissues due to increased vascular permeability $^{39}$. Thus, polymeric micelles can be employed to administer chemotherapeutics in a controlled and targeted manner with high concentration in the tumoural cells and reduced side effects.

However, the targeting ability of polymeric micelles is limited due to low drug loading ${ }^{41,42}$ and low drug incorporation stability ${ }^{41}$ which cause the loaded drug to be released before getting to the site of action. Consequently, manipulation of the production parameters and the design of the inner core can improve drug loading and drug incorporation stability, respectively ${ }^{41,42}$. Lipid moieties, such as cholesterol and fatty acyl carnitines, can also be employed to impart good stability to the 
polymeric micelles. This is based on increased hydrophobic interaction between the polymeric chains in the inner core due to presence of fatty acid acyls (e.g. diacyllipid) $)^{39}$.

Polymeric micelles have been employed for targeted and intracellular delivery ${ }^{42}$, sustained release and parenteral delivery ${ }^{39}$

\section{Nanocapsules}

Nanocapsules are spherical hollow structures in which the drug is confined in the cavity and is surrounded by a polymer membrane ${ }^{43}$. They were developed over 30 years ago. Sizes between 50 and $300 \mathrm{~nm}$ are preferred for drug delivery and they may be filled with oil which can dissolve lipophilic drugs. They have low density, high loading capacity and are taken up by the mononuclear phagocyte system, and accumulate at target organs such as liver and spleen ${ }^{44}$.

Nanocapsules can be employed as confined reaction vessels, protective shell for cells or enzymes, transfection vectors in gene therapy, dye dispersants, carriers in heterogenous catalysis, imaging and drug carriers ${ }^{45,46}$. They are known to improve the oral bioavailability of protein and peptides which include insulin, elcatonin and salmon calcitonin $^{43,47}$. Encapsulation of drugs such as ibuprofen $^{44}$ within nanocapsules protects liable drugs from degradation, reduces systemic toxicity, provide controlled release and mask unpleasant taste ${ }^{48}$. Due to their high stability and low permeability, drugs may not be loaded into the capsules after formulation and also the release of the drug at target site may be difficult. To improve on their permeability, they are made responsive to physiological factors such as $\mathrm{pH}^{49}$.

\section{Nanoemulsions}

Nanoemulsions are emulsions with droplet size below $1 \mu$ but usually between 20 and $200 \mathrm{~nm}{ }^{50,51}$. Unlike microemulsions which are white in colour due to their light scattering ability, nanoemulsions whose nanosize is often smaller than visible wavelength, are transparent ${ }^{50,52}$. Nanoemulsions are biodegradable, biocompatible, easy to produce and used as carriers for lipophilic drugs which are prone to hydrolysis. They are employed as a sustained release delivery system for depot formation via subcutaneous injection ${ }^{51}$. They enhance gastrointestinal absorption and reduce inter- and intra-subject variability for various drugs. Due to their very large interfacial area, they exhibit excellent drug release profile ${ }^{53}$. Nanoemulsions have been studied and developed for parenteral, oral, ocular, pulmonary and dermal deliveries ${ }^{50}$.

Stability against sedimentation is attained based on the nano size of the droplets because the sedimentation rate due to gravity is less than Brownian movement and diffusion $^{50}$. Unlike microemulsions, nanoemulsions are metastable and can be destabilized by Ostwald ripening whereby the small droplets dissolve and their mass is taken up by the large droplets and depletion induced flocculation due to addition of thickening polymers. When this happens, the nanoemulsion becomes opaque and creaming will occur ${ }^{54}$. However, addition of a small amount of a second oil with low solubility into the aqueous phase and addition of a second surfactant may reduce Ostwald ripening ${ }^{50}$. Also, a number of factors during production should be controlled ${ }^{52}$. These factors include selecting an appropriate composition, controlling the order of addition of components, applying the shear in a manner that will effectively rupture the droplets, and ensuring that the dispersed phase molecules are insoluble in the continuous phase so that Ostwald ripening does not occur rapidly ${ }^{52}$.

\section{Ceramic nanoparticles}

Ceramic nanoparticles are particles fabricated from inorganic compounds with porous characteristics such as silica, alumina and titania ${ }^{55-57}$. They can be prepared with 
the desired size, shape and porosity. Their sizes are less than 100 nm and are able to avoid uptake by the reticulo-endothelial system as foreign bodies. Entrapped molecules such as drugs, proteins and enzymes are protected from denaturation at physiological $\mathrm{pH}$ and temperature as neither swelling nor change in porosity occurs ${ }^{57}$. Hence, they are effective in delivering proteins and genes. However, these particles are not biodegradable and so there is concern that they may accumulate in the body and cause harmful effects ${ }^{56}$.

\section{Metallic nanoparticles}

Metallic nanoparticles include iron oxide, gold, silver, gadolinium and nickel which have been studied for targeted cellular delivery ${ }^{58}$. Gold exhibits favourable optical and chemical properties at nanoscale for biomedical imaging and therapeutic applications ${ }^{56}$. It can be manipulated to obtain the desired size in the range of 0.8 to $200 \mathrm{~nm}$. The surface can be modified with different functional groups for gene transfection, modified into gene delivery vector by conjugation and also modified to target proteins and peptides to the cell nucleus ${ }^{58,59}$. Gadolinium has been studied for enhanced tumour targeted delivery by modification of the nanoparticles with folate, thiamine and poly (ethylene glycol). Modification with folate was reported to enhance the recognition, internalization and retention of gadolinium nanoparticles in tumour cells ${ }^{58}$. Metallic nanoparticles have large surface area thereby incorporating a high drug dose. However, the toxicity of metallic nanoparticles is of concern.

\section{Carbon nanomaterials}

These include carbon nanotubes and fullerenes. Fullerenes are carbon allotrope made up of 60 or more carbon atoms with a polygonal structure. Nanotubes have been used for their high electrical conductivity and excellent strength ${ }^{56}$. These materials are being studied for therapeutic applications. Fullerenes can be functionalized for delivery of drugs and biomolecules across cell membrane to the mitochondria ${ }^{58}$. Carbon nanotubes' unique properties including low cytotoxicity and good biocompatibility attract their use as vector system in target delivery of drugs, proteins and genes ${ }^{58}$. However, toxicity of carbon nanotubes is of concern ${ }^{60}$. Carbon nanotubes may cause inflammatory and fibrotic reactions.

\section{METHODS OF FABRICATION}

The method employed for the fabrication of nanostructures depends on the type and the desired properties of the nanostructure to be produced. Methods of preparing of polymeric nanoparticles have been reviewed ${ }^{15,61}$ and they include ionic gelation, coacervation, solvent evaporation, spontaneous emulsification/solvent diffusion, salting out/emulsification-diffusion, supercritical fluid technology and polymerization. Depending on the materials utilized, such as phospholipids and glycolipids, the desired liposome structure can be prepared by sonication, electroformation, extrusion from diluted lamellar dispersions, high-shear homogenization, reverse-phase evaporation, gel exclusion chromatography, freezelyophilization, calcium-induced fusion, detergent dialysis and ultracentrifugation ${ }^{62-65}$.

Syntheses of dendrimers include the use of Tomalia's divergent growth approach, convergent growth approach, and orthogonal coupling strategy 26, 66, 67, while solid lipid nanoparticles are prepared by high shear homogenization, ultrasound dispersion technique, high pressure homogenization, solvent emulsification/evaporation, microemulsion and solvent diffusion ${ }^{33,68,69}$.

Methods of preparing polymeric micelles include dialysis, solution-casting, direct dissolution, ${ }^{70,71}$ while nanocapsules are prepared by microemulsion, miniemulsion polymerization and interfacial polymerization $^{43,72}$. Nanoemulsions are prepared by spontaneous emulsification, high pressure and ultrasonic homogenization ${ }^{51,73}$. Ceramic nanoparticles are produced by template 
synthesis $^{74}$, hot pressing technique ${ }^{75}$ and by controlled hydrolysis in micellar medium ${ }^{76}$.

Metallic nanoparticles are synthesized by gas phase deposition and electron beam lithography. However, co-precipitation gives appreciable control of size, composition and sometimes, shape of the nanoparticles ${ }^{77}$. Gold nanoparticles are prepared in organic solvents (Brust-Schiffrin method), and also by chemical reduction of chloride precursor in aqueous conditions (Turkevich method) ${ }^{78}$

Carbon nanomaterials are prepared by template synthesis ${ }^{79}$, the carbon-arc discharge technique, catalytic chemical vapour deposition and laser ablation ${ }^{80,81}$

\section{CHALLENGES OF NANO DRUG DELIVERY}

Although nanotechnology in drug delivery has been successful, as evidenced by some nano drug products in the market, not all approaches have met with the same success. New nanomaterials being developed come with challenges which have to be surmounted. However some of the challenges encountered have been and are still being tackled by modification of the physicochemical characteristics of the nanomaterials to improve on properties such as long circulation in the blood, increased functional surface area, protection of incorporated drug from degradation, crossing of biological barriers and site-specific targeting.

Another challenge of research and development (R\&D) of nanomaterials for drug delivery is large scale production. There is always a need to scale up laboratory or pilot technologies for eventual commercialization. A number of nano drug delivery technologies may not be scalable due to the method and process of production and high cost of materials employed. The challenges of scaling up include low concentration of nanomaterials, agglomeration and the chemistry process - it is easier to modify nanomaterials at laboratory scale for improved performance than at large scale. Maintaining the size and composition of nanomaterials at large scale is also a challenge.

Despite the number of patents for nano drug delivery technologies, commercialization is still at its early stage. This is partially due to the fact that most of the research studies in nano drug delivery are carried out by researchers in academia. Therefore, for these technologies to get to the market there has to be increased partnership with the pharmaceutical companies. Unfortunately, a number of the major pharmaceutical industries are yet to consider nanotechnology as one of their priorities ${ }^{82}$ due to lack of regulatory guidelines and challenges of scaling up. . However, it is envisaged that with the expiration of more patents and market loss, more pharmaceutical industries will take up the production of nano drug products in order to compete favourably.

Advances in nano drug delivery technology also provide new challenges for regulatory control. There is an increasing need to have regulations that would account for physicochemical and pharmacokinetic properties of nano drug products, which are different from conventional drug products. The United States' Food and Drug Administration (FDA) and the European Medicines Evaluation Agency (EMEA) have taken the initiative to identify some possible scientific and regulatory challenges. ${ }^{82}$ Furthermore, the International Organization for Standardization has set up a technical committee (TC 229) for the field of nanotechnologies to develop standards pertaining to terminology and nomenclature; measurement and characterization; and health, safety and environment amongst other standards. These standards are still under development.

\section{Safety issues}

With increased R\&D work on nano drug delivery, emerges concerns about the safety of the nanotechnologies in humans. Some of 
the nanomaterials are biodegradable while some are not; furthermore, the side effects of the by-products present a huge concern. Materials which may be safe at macroscale may not be at nanoscale since there may be change in physicochemical characteristics at nanoscale. These nanomaterials may not clear completely from the body and their accumulation may have several possible effects $^{83,84}$.

Safety and possible impact nanomaterials should not be considered for the patient population alone but also for the entire manufacturing and disposal processes. Conventional safety measures in a pharmaceutical factory may not be appropriate for the development and fabrication of nanomaterials. Also extra measures are to be taken to protect the environment from increased envisaged negative impacts of nanomaterials.

Although reduced cost to the patients is envisaged to be one of the advantages of nanotechnology since fewer materials are expected to go into production as compared to bulk production; it is doubtful if this will be so, as successful commercialization will be expensive. There is also the general public reluctance to embrace nanotechnology based on the unavailability of documented safety guidelines. However, despite these challenges, nano drug delivery is a development that cannot be ignored and so the challenges will be tackled with time.

\section{Commercially available nano drug delivery systems}

Despite the challenges which include the huge volume of expenditure involved and the regulatory stages (preclinical and clinical stages - Phases 1 - 4) which are mandatory in order to obtain regulatory approval before a drug can get into the market, some nano drug delivery systems have made it to the market. Table 1 shows the list of some of nano drug delivery systems in the market:

\section{CONCLUSION}

The increasing awareness and R\&D in the area of nano drug delivery would continue to change the whole concept of medicines including aspects such as product characteristics, bioavailability, pharmacokinetics, stability, drug use, and toxicity in human

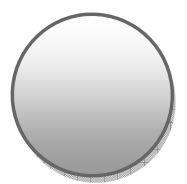

A

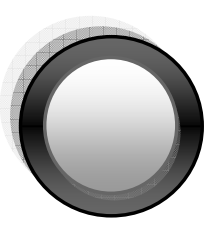

$\mathrm{E}$

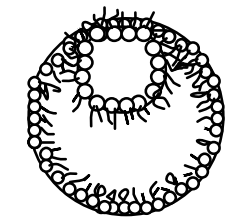

B

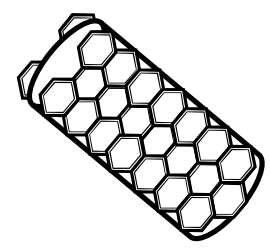

$\mathrm{F}$

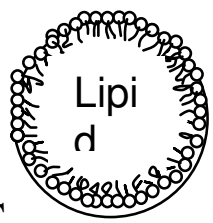

$\mathrm{D}$
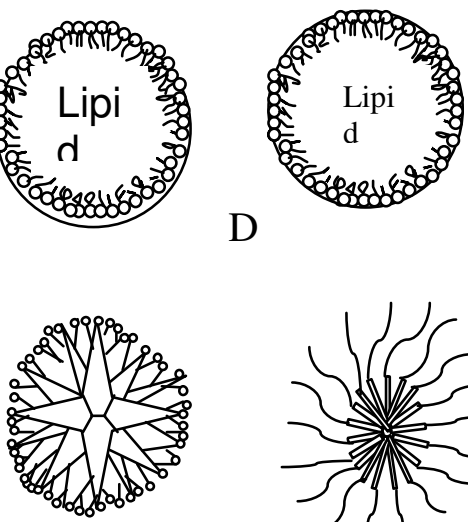

G

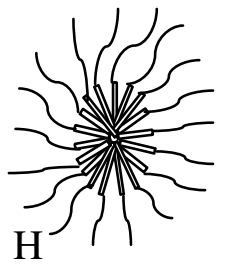

Figure 1: Illustration of some nanostructures A) Spherical polymeric nanoparticle; B) Liposome; C) Solid lipid nanoparticles - solid lipid enclosed within; D) Nanoemulsion - liquid enclosed within; E) Nanocapsule - hollow; F) Carbon nanotube; G) Dendrimer; I) Polymeric micelle. 
Table 1a: Nano drug delivery systems in the market ${ }^{82}$

\begin{tabular}{|c|c|c|c|c|}
\hline $\begin{array}{l}\text { Type of } \\
\text { nanostructure }\end{array}$ & Trade name & Active ingredient & Indication & Company \\
\hline \multirow[t]{8}{*}{$\begin{array}{l}\text { Polymeric } \\
\text { nanoparticles }\end{array}$} & Adagen & $\begin{array}{l}\text { Adenosine } \\
\text { deaminase }\end{array}$ & $\begin{array}{l}\text { Adenosine } \\
\text { deaminase (ADA) } \\
\text { enzyme deficiency }\end{array}$ & $\begin{array}{l}\text { Enzon Pharmaceuticals Inc., } \\
\text { Bridgewater, NJ, USA }\end{array}$ \\
\hline & Onscaspar & L-asparaginase & $\begin{array}{l}\text { Acute } \\
\text { lymphoblastic } \\
\text { leukaemia }\end{array}$ & $\begin{array}{l}\text { Enzon Pharmaceuticals Inc., } \\
\text { NJ, USA }\end{array}$ \\
\hline & Copaxone & Glatiramer Acetate & $\begin{array}{l}\text { Relapsing-remitting } \\
\text { multiple sclerosis }\end{array}$ & $\begin{array}{l}\text { Teva Pharmaceuticals, Tikva, } \\
\text { Isreal }\end{array}$ \\
\hline & Macugen & $\begin{array}{l}\text { Pegaptanib } \\
\text { Sodium }\end{array}$ & $\begin{array}{l}\text { All types of } \\
\text { neovascular age- } \\
\text { related macular } \\
\text { degeneration }\end{array}$ & $\begin{array}{lll}\text { Nektar } & \text { Therapeutics, } & \text { San } \\
\text { Carlos, CA, USA; } & \text { OSI } \\
\text { Pharmaceuticals, } & \text { Melville, NY, } \\
\text { USA } & & \end{array}$ \\
\hline & Pegasys & $\begin{array}{l}\text { Pegylated } \\
\text { interferon alfa-2a }\end{array}$ & Hepatitis C & Nektar Therapeutics, CA, USA \\
\hline & Neulasta & Pegfilgrastim & Neutopenia & $\begin{array}{l}\text { Nektar Therapeutics, CA, USA; } \\
\text { Amgen Inc, Thousand Oaks, } \\
\text { CA, USA }\end{array}$ \\
\hline & PEG-INTRON & $\begin{array}{l}\text { Peginterferon alfa- } \\
2 \mathrm{~b}\end{array}$ & Hepatitis C & Nektar therapeutics, CA, USA \\
\hline & Somavert & Pegvisomant & Acromegaly & Nektar therapeutics, CA, USA \\
\hline \multirow[t]{2}{*}{ Liposomes } & Abelcet & Amphotericn B & Fungal infections & $\begin{array}{l}\text { Enzon Pharmaceuticals Inc., } \\
\text { Bridgewater, NJ, USA }\end{array}$ \\
\hline & Depocyt & Cytarabine & $\begin{array}{l}\text { Lymphomatous } \\
\text { meningitis }\end{array}$ & $\begin{array}{l}\text { Enzon Pharmaceuticals Inc., } \\
\text { NJ, USA }\end{array}$ \\
\hline \multirow[t]{11}{*}{ Liposomes } & AmBisome & Amphotericn B & Fungal infections & $\begin{array}{lll}\text { Gilead Sciences } & \text { Inc., } & \text { Foster } \\
\text { City, CA, USA } & & \end{array}$ \\
\hline & Daunoxome & Daunorubicin & Kaposi's sarcoma & Gilead Sciences Inc., CA, USA \\
\hline & Myocet & Doxorubicin & $\begin{array}{l}\text { Advanced breast } \\
\text { cancer }\end{array}$ & $\begin{array}{l}\text { Zeneus/Cephalon, Inc., Frazer, } \\
\text { PA, USA }\end{array}$ \\
\hline & Epaxal & $\begin{array}{l}\text { Inactivated } \\
\text { Hepatitis A virus }\end{array}$ & Hepatitis A & $\begin{array}{l}\text { Berna Biotech, Bern, } \\
\text { Switzerland }\end{array}$ \\
\hline & Inflexal V & $\begin{array}{l}\text { Inactivated } \\
\text { influenza surface } \\
\text { antigen }\end{array}$ & Influenza & $\begin{array}{l}\text { Berna Biotech, } \\
\text { Switzerland }\end{array}$ \\
\hline & DepoDur & Morphine & Analgesia & $\begin{array}{l}\text { EKR Therapeutics, Bedminster, } \\
\text { NJ, USA }\end{array}$ \\
\hline & Visudyne & Verteporfin & $\begin{array}{l}\text { Age-related } \\
\text { macular } \\
\text { degeneration }\end{array}$ & $\begin{array}{l}\text { QLT Inc., Vancouver, British } \\
\text { Colombia, Canada; Norvatis, } \\
\text { Basel, Switzerland }\end{array}$ \\
\hline & Doxil & Doxorubicin & $\begin{array}{l}\text { Ovarian cancer and } \\
\text { Kaposi's sarcoma }\end{array}$ & $\begin{array}{l}\text { Ortho Biotech, Bridgewater, NJ, } \\
\text { USA }\end{array}$ \\
\hline & Caelyx & Doxorubicin & $\begin{array}{l}\text { Ovarian cancer, } \\
\text { Kaposi's sarcoma } \\
\text { \& breast cancer }\end{array}$ & $\begin{array}{l}\text { Schering-Plough, Kenilworth, } \\
\text { NJ, USA }\end{array}$ \\
\hline & Estrasorb & Estradiol & $\begin{array}{l}\text { Menopausal - Hot } \\
\text { flushes }\end{array}$ & Novavax, Rockville, MD, USA \\
\hline & Survanta & $\begin{array}{l}\text { Beractant (bovine } \\
\text { lung homogenate) }\end{array}$ & $\begin{array}{l}\text { Respiratory } \\
\text { distress syndrome }\end{array}$ & Abbott Laboratories, IL, USA \\
\hline \multirow[t]{2}{*}{ Liposomes } & Alveofact & $\begin{array}{l}\text { Bovactant(bovine } \\
\text { lung lavage) }\end{array}$ & $\begin{array}{l}\text { Respiratory } \\
\text { distress syndrome }\end{array}$ & $\begin{array}{l}\text { Boehringer Ingelheim } \mathrm{GmbH} \text {, } \\
\text { Ingelheim, Germany }\end{array}$ \\
\hline & Curosurf & $\begin{array}{l}\text { Poractant alfa } \\
\text { (porcine lung } \\
\text { homogenate) } \\
\end{array}$ & $\begin{array}{l}\text { Respiratory } \\
\text { distress syndrome }\end{array}$ & $\begin{array}{l}\text { Chiesi Farmaceutici } \\
\text { Parma, Italy }\end{array}$ \\
\hline $\begin{array}{l}\text { Polymeric } \\
\text { micelles }\end{array}$ & Genexol-PM & Paclitaxel & $\begin{array}{l}\text { Cancer } \\
\text { chemotherapy }\end{array}$ & $\begin{array}{l}\text { Samyang Pharmaceutical, } \\
\text { Daejeon City, Korea }\end{array}$ \\
\hline
\end{tabular}


Table 1B: Nano drug delivery systems in the market (contd.)

\begin{tabular}{|c|c|c|c|c|}
\hline $\begin{array}{l}\text { Type of } \\
\text { nanostructure }\end{array}$ & Trade name & Active ingredient & Indication & Company \\
\hline $\begin{array}{l}\text { Nanocrystalline } \\
\text { drugs }\end{array}$ & Rapamune & Sirolimus & $\begin{array}{l}\text { Immunosuppressa } \\
\mathrm{nt}\end{array}$ & $\begin{array}{l}\text { Elan Corporation, Dublin, } \\
\text { Ireland; Wyeth Pharmaceutical, } \\
\text { Madison, NJ, USA }\end{array}$ \\
\hline & Emend & Aprepitant & Antiemetic & $\begin{array}{l}\text { Elan Corporation, Dublin, } \\
\text { Ireland; Merck and Co., Inc. } \\
\text { Whitehouse Station, NJ, USA }\end{array}$ \\
\hline & Tricor & fenofibrate & Hyperlipidemia & $\begin{array}{lll}\text { Elan } & \text { Corporation, } & \text { Dublin, } \\
\text { Ireland; Abbott Labs, Illinois, } \\
\text { USA }\end{array}$ \\
\hline & Megace & Megestrol acetate & Anorexia, Cachexia & $\begin{array}{l}\text { Elan Corporation, Dublin, } \\
\text { Ireland; Par Pharmaceuticals, } \\
\text { Woodcliff Lake, NJ, USA }\end{array}$ \\
\hline $\begin{array}{l}\text { Protein (albumin) } \\
\text { nanoparticles }\end{array}$ & Abraxane & Paclitaxel & $\begin{array}{l}\text { Metastatic breast } \\
\text { cancer }\end{array}$ & $\begin{array}{llr}\text { Abraxis } & \text { BioScience, } & \text { Los } \\
\text { Angeles, CA, USA; } & \text { Astra } \\
\text { Zeneca, London, UK } & \\
\end{array}$ \\
\hline $\begin{array}{l}\text { Lipid colloidal } \\
\text { dispersion }\end{array}$ & Amphotec & Amphotericin B & Fungal infections & InterMune, Brisbane, CA, USA \\
\hline
\end{tabular}

\section{CONCLUSION}

as well as animal and plant diseases. This in itself poses emormous chalemges to the formulation scientist who has to keep abreast of rapid developments in this field. A whole segement of $R$ \& $D$ has opened up, posing great challenges to equipment manufacturers, material scientists, pharmaceutical researchers, and regulatory agencies. It is anticipated that better understanding and application of nanotechnology for effective drug delivery would ultimately enhance efficacy of treatment and patient drug use compliance.

\section{REFERENCES}

1. Yih TC, Al-Fandi M. Engineered nanoparticles as precise drug delivery systems. J. Cellular Biochemistry, 2006; 97: 1184-1190.

2. Kingsley JD, Dou $H$, Morehead J, Rabinow $B$, Gendelman HE, Destache CJ. Nanotechnology: a focus on nanoparticles as drug delivery system. J. Neuroimmune Pharmacol., 2006; 1: 340-35.

3. Arias JL, Ruiz MA, López-viota M, Delgado AV. Poly(alkylcyanoacrylate) colloidal particles as vehicles for antitumour drug delivery: a comparative study. Colloids and Surfaces B: Biointerfaces, 2008; 62: 64-70.

4. Singh J, Pandit $S$, Bramwell VW, Alpar $\mathrm{OH}$. Diphtheria toxoid loaded-( $\varepsilon$-caprolactone) nanoparticles as mucosal vaccine delivery systems. Methods, 2006; 38: 96-106.

5. Kim IS, Kim S-H. Development of polymeric nanoparticulate drug delivery systems: evaluation of nanoparticles based on biotinylated poly (ethylene glycol) with sugar moiety. Int. J. Pharm., 2003; 257: 195-203.

6. Ikuta $K$, Mori $T$, Yamamoto $T$, Niidome $T$, Shimokawa $H$, Katayama Y. Development of polymeric drug delivery system for recognizing vascular endothelial dysfunction. Bioorganic and Medicinal Chemistry, 16: 2811-2818.

7. Damgé C, Maincent $P$, Ubrich, N. (2007) Oral delivery of insulin associated to polymeric nanoparticles in diabetic rats. J. Controlled Release, 2008; 117: 163-170.

8. Härtig $W$, Paulke B-R, Varga $C$, Seeger J, Harkany $T$, Kacza J. Electron microscopic analysis of nanoparticles delivering thioflavin- $T$ after intrahippocampal injection in mouse: implications for targeting $B$-amyloid in Alzheimer's disease. Neuroscience Letters, 2003; 338(2): 174-176.

9. Alvarez-Román R, Naik A, Kalia YN, Guy RH, Fessi $H$. Skin penetration and distribution of polymeric nanoparticles. J. Controlled Release, 2004; 99: 53-62.

10. Dai J, Nagai T, Wang X, Zhang T, Meng M, Zhang Q. $p H$-sensitive nanoparticles for improving the oral bioavailability of cyclosporine $A$. Int. J. Pharm, 2004; 280: 229-240.

11. Moussaoui N, Cansell M, Denizot A. Marinosomes, marine lipid-based liposomes: physical characterization and potential application in cosmetics. Int. J. Pharm., 2002; 242 (1-2): 361-385.

12. Nenadis N, Zafiropoulou I, Tsimidou M. Commonly used food antioxidants: a comparative study in 
dispersed systems. Food Chemistry, 2003; 82 (3): 403-407.

13. Alonso A, Goñi FM, Buckley JT. Lipids favoring inverted phase enhance the ability of aerolysm to permeabilize liposome bilayers. Biochemistry, 2000; 39 (46): 14019-14024.

14. Banerjee R. Liposomes: applications in medicine. Journal of Biomaterials Applications, 2001; 16(1): 3-21.

15. Soppimath KS, Aminabhavi TM, Kulkarni AR Rudzinski WE. Biodegradable polymeric nanoparticles as drug delivery devices. J. Controlled Release, 2001; 70(1-2): 1-20.

16. Lim HJ, Cho EC, Shim J, Kim D-H, An EJ, Kim J. Polymer-associated liposomes as a novel delivery system for cyclodextrin-bound drugs. J. Colloid and Interface Science, 2008; 320: 460-468.

17. Sihorkar V, Vyas SP. Potential of polysaccharide anchored liposomes in drugs delivery, targeting and immunization. J. Pharm Pharmaceut Sci., 2001; 4(2): 138-158.

18. Bakowsky H, Richter T, Kneuer C, Hoekstra D, Rothe U, Bendas G, Ehrhardt C, Bakowsky U. Adhesion characteristics and stability assessment of lectin-modified liposomes for site-specific drug delivery. Biochimica et Biophysica Acta, 2008; 1778: 242-249.

19. Qiu Y, Gao Y, Hu K, Li F. Enhancement of skin permeation of docetaxel: a novel approach combining microneedle and elastic liposomes. J. Controlled Release, 2008; 129: 144-150.

20. Jia $Y$, Joly $H$, Omri $H$. Liposomes as a carrier for gentamicin delivery: development and evaluation of the physicochemical properties. Int. J. Pharm., 2008; 359: 254-263.

21. Zaru M, Mourtas S, Klepetsanis P, Fadda AM, Antimisiaris SG. Liposomes for drug delivery to the lungs by nebulisation. Eur. J. Pharm. Biopharm., 2007; 67: 655-666.

22. Budai L, Hajdú M, Budai M, Gróf P, Béni S, Noszál $B$, Klebovich I, Antal I. Gels and liposomes in optimized ocular drug delivery: studies on ciprofloxacin formulations. Int. J. Pharm., 2007; 343: 34-40.

23. Dat $A A$, Joshi MD, Patravale VB. Parasitic diseases: liposomes and polymeric nanoparticles versus lipid nanoparticles. Advanced Drug Delivery Reviews, 2007; 59: 505-521.

24. Barry BW. Novel mechanisms and devices to enable successful transdermal drug delivery. Eur. J. Pharm. Sci., 2001; 14(2): 101-114.

25. Barry BW. Is transdermal drug delivery research still important today? Drug Discovery Today, 2001; 6(19): 967-971.

26. Gilles ER, Fréchet JMJ. Dendrimers and dendritic polymers in drug delivery. Drug Discovery Today, 2005; 10(1): 35-43.

27. Gupta U, Agashe HB, Asthana A, Jain NK. A review of in vitro-in vivo investigations on dendrimers: the novel nanoscopic drug carriers. Nanomedicine:NBM, 2006; 2: 66-73.
28. Cloninger MJ. Biological application of dendrimers. Current Opinion in Chemical Biology, 2002; 6(6): $742-748$.

29. Beezer $A E$, King ASH, Martin IK, Mitchel JC, Twyman LJ, Wain CF. Dendrimers as potential drug carriers; encapsulation of acidic hydrophobes within water soluble PAMAM derivatives. Tetrahedron, 2003; 59(22): 38733880.

30. Wolinsky JB, Grinstaff MW. Therapeutic and diagnostic applications of dendrimers for cancer treatment. Advanced Drug Delivery Reviews, 2008; 60: 1037-1055.

31. Najlah M, Freeman S, Attwood D, D'Emanuele A. In vitro evaluation of dendrimer prodrug for oral drug delivery. Int. J. Pharm., 2007; 336: 183190.

32. Najlah M, D'Emanuele A. Crossing cellular barriers using dendrimer nanotechnologies. Current Opinion in Pharmacology, 2006; 6: 522-527.

33. Müller $R H$, Mäder $K$, Gohla $S$. Solid lipid nanoparticles (SLN) for controlled drug delivery- a review of the state of the art. Eur. J. Pharm. Biopharm., 2000; 50(1): 161-177.

34. Wissing SA, Kayser $O$, Müller RH. Solid Lipid nanoparticles for parenteral drug delivery. Advanced Drug Delivery Reviews, 2004; 56(9): 1257-1272.

35. Puglia C, Blasi P, Rizza I, Schoubben A, Bonina F, Rossi C, Ricc M. Lipid nanoparticles for prolonged topical delivery: an in vitro and in vivo investigation. Int. J. Pharm., 2008; 357:295-304.

36. Cavalli $R$, Gasco MR, Chetoni P, Burgalassi $S$, Saettone MF. Solid Lipid nanoparticles (SLN) as ocular delivery system for tobramycin. Int. J. Pharm., 2002; 238: 241-245.

37. Casadei MA, Cerreto F, Cesa S, Giannuzzo, M, Feeney M, Marianecci C, Paolicelli P. Solid lipid nanoparticles incorporated in dextran hydrogels: a new drug delivery system for oral formulations. Int. J. Pharm., 2006; 325:140146.

38. Liu J, Gong T, Fu H, Wang C, Wang X, Chien $Q$, Zhang $Q$, He Q, Zhang Z. Solid lipid nanoparticles for pulmonary delivery of insulin. Int. J. Pharm., 2008; 356: 333-344.

39. Jones $M-C$, Leroux J-C. Polymeric micelles-a new generation of colloidal drug carriers. Eur. J. Pharm. Biopharm., 1999; 48(2): 101-111.

40. Nishiyama N, Kataoka K. Current state achievements and future prospects of polymeric micelles as nanocarriers for drug and gene delivery. Pharmacology and Therapeutics, 2006; 112: 630-648.

41. Yamamoto $T$, Yokoyam $M$, Opanasopit $P$, Hayama A, Kawano K, Maitani, Y. What are determining factors for stable drug incorporation into polymeric micelle carriers? Consideration on physical and chemical characters of the micelle inner core. J. Controlled Release, 2007; 123: 11-18. 
42. Seow $W Y$, Xue JM, Yang $Y-Y$. Targeted and intracellular delivery of paclitaxel using multifunctional polymeric micelles. Biomaterials, 2007; 28(9): 1730-1740.

43. Tiark F, Landfester K, Antonietti M. Preparation of polymeric nanocapsules by miniemuslion polymerization. Langmuir, 2001; 17: 908-918.

44. Jiang $B$, Hu L, Gao C, Shen J. Crosslinked polysaccharide nanocapsules: preparation and drug release properties. Acta Biomaterialia, 2006; 2: 9-18.

45. Meier W. Polymer nanocapsules. Chem. Soc. Rev., 2000; 29: 295-303.

46. Reinhold C. Smart tailoring of nanocapsules. NanoToday, 2007; 2(2): 13.

47. Prego C, Torres D, Fernandez-Megia E, NovoaCarballal R, Quiñoá E, Alonso MJ. Chitosan Peg nanocapsules as new carriers for oral peptide delivery: effect of chitosan pegylation degree. J. Controlled Release, 2006; 111: 299308.

48. Whelan J. Nanocapsules for controlled delivery. Drug Discovery Today, 2001; 6(23): 11831184.

49. Sauer M, Meier W. Responsive nanocapsules. Chem. Commun, 2001, 55-56.

50. Solans C, Izquierdo P, Nolla J, Azemar N, GarciaCelma MJ. Nano-emulsion. Current Opinion in Colloid and Interface Science, 2005; 10: 102110.

51. Santos-Magalhães NS, Pontes A, Pereira VMW, Caetano MNP. Colloidal carriers for benzathin penicillin G: nanoemulsions and nanocapsules. Int. J. Pharm., 2000; 208 (1-2): 71-80.

52. Chiesa M, Garg J, Kang YT, Chen G. Thermal conductivity and viscosity of water-in-oil nanoemulsions. Colloids Surf. A: Physicochem. Eng. Aspects, Doi:10.1016/j.colsurfa.2008.05.028.

53. Brüsewitz $C$, Schendler A, Funke A, Wagner T, Lipp $R$. Novel poloxamer-based nanoemulsions to enhance the intestinal absorption of active compounds. Int. J. Pharm., 2007; 329: 1173181.

54. Sonneville-Aubrun $O$, Simonnet J-T, L'Alloret F. Nanoemulsions: a new vehicle for skin care products. Advances in Colloid and interface Science, 2004; 108-109: 145-149.

55. Orive G, Hernández RM, Gascón AR, Pedraz JL. Micro and nano drug delivery systems in cancer therapy. Cancer Therapy, 2005; 3: 131138.

56. Medina C, Santos-Martinez MJ, Radomski A, Corrigan OI, Radomski MW. Nanoparticles: Pharmacological and toxicological significance. British Journal of Pharmacology, 2007; 150: 552-558.

57. Rawat $M$, Singh $D$, Saraf S, Saraf S. Nanocarriers: promising vehicle for bioactive drugs. Biol. Pharm. Bull., 2006; 29(9): 1790-1798.

58. $X u Z P$, Zeng $Q H, L u G Q, Y u A B$. Inorganic nanoparticles as carriers for efficient cellular delivery. Chemical Engineering Science, 2006; 61: 1027-1040.

59. Penn SC, He I, Natan MJ. Nanoparticle for bioanalysis. Current Opinion in Chemical Biology, 2003; 7: 609-615.

60. Muller J, Huaux F, Lison D. Respiratory toxicity of carbon nanotubes: how worried should we be? Carbon, 2006; 44(6): 1048-1056.

61. Mohanraj VJ, Chen Y. Nanoparticles - A review. Tropical Journal of Pharmaceutical Research, 2006; 5(1): 561-573.

62. Šegota S, Težak D. Spontaneous formation of vesicles. Advances in Colloid and Interface Science, 2006; 121: 51-75.

63. Storm G, Crommelin DJA. Liposomes: quo Vadis? Pharmaceutical Science and Technology Today, 1998; 1(1): 19-31.

64. Huang S-L. Liposomes in Ultrasonic drug and gene delivery. Advanced Drug Delivery Reviews, 2008; 60: 1167-1176.

65. Sharma A, Sharma US. Liposomes in drug delivery: progress and limitations. Int. J. Pharm., 1997; 154:123-140.

66. Liu M, Fréchet JMJ Designing dendrimers for drug delivery. Pharmaceutical Sciences and Technology Today, 1999; 2(10): 393-401.

67. Sadler K, Tam JP. Peptide dendrimers: applications and synthesis. Reviews in Molecular biotechnology, 2002; 90(3-4): 195-229.

68. Mehnert W, Mäder K. Solid lipid nanoparticles production, characterization and applications. Advanced Drug Delivery Reviews, 2001; 47(23): 165-196.

69. Huo J, Zhou S-W. New research on development of solid lipid nanoparticles. Journal of Medical Colleges of PLA, 2007; 22(6): 385-390.

70. Lukyanov AN, Torchilin VP. Micelles from lipid derivatives of water-soluble polymers as delivery systems for poorly soluble drugs. Advanced Drug Delivery Reviews, 2004; 56 : 1273-1289.

71. Gaucher $G$, Dufresne $M-H$, Sant VP, Kang $N$, Maysinger $D$, Leroux J-C. Block copolymer micelles: preparation, characterization and application in drug delivery. J. Controlled Release, 2005; 109: 169-188.

72. Pikaksuteepong T, Davies NM, Tucker IG, Rades T. Factors influencing the entrapment of hydrophilic compounds in nanocapsules prepared by interfacial polymerization of waterin-oil microemulsions. Eur. J. Pharm. Biopharm., 2002; 53(3): 335-342.

73. Tal-Figiel B, Figiel W. Micro- and nanoemulsions in cosmetic and pharmaceutical products. Journal of Dispersion Science and Technology, 2008; 29(4): 611-616.

74. Son JS, Bai X, Nan A, Ghandehari $H$, Lee $S B$. Template synthesis of multifunctional nanotubes for controlled release. J. Controlled Release, 2006; 114(2): 143-152.

75. Zhao J, Ai X, Lü Z. Preparation and characterization of Si3N4/TiC nanocomposite ceramics. Materials letters, 2006; 60: 2810-2813. 
Ochekpe et al

76. Roy I, Ohulchanskyy TY, Pudavar HE, Bergey EJ, Oseroff AR, Morgan J, Dougherty TJ, Prasad $P N$. Ceramic-based nanoparticles entrapping water-insoluble photosensitizing anticancer drugs: a novel drug-carrier system for photodynamic therapy. J. American Chemical Society, 2003; 125: 7860-7865.

77. Gupta AK, Gupta M. Synthesis and surface engineering of iron oxide nanoparticles for biomedical applications. Biomaterials, 2005; 26(18): 3995-4021.

78. Aslam M, Fu L, Su M, Vijayamohanan K, Dravid $V P$. Novel one-step synthesis of aminestabilized aqueous colloidal gold nanoparticles. J. Mater. Chem., 2004; 14:1795-1797.

79. Son JS, Bai $X$, Lee SB. Inorganic hollow nanoparticles and nanotubes in nanomedicine part I: drug/gene delivery application. Drug Discovery Today, 2007; 12(15-16): 650-656.
80. Foldvari $M$, Bagonluri $M$. Carbon nanotubes as functional excipients for nanomedicine: $I$. Pharmaceutical properties. Nanomedicine:NBM, 2008; $\quad x x: 1-10$, doi:10.1016/j.nano.2008.04.002.

81. Sinha N, Yeow JT-W. Carbon nanotubes for biomedical applications. IEEE Trans Nanobioscience, 2005; 4(2): 180-195.

82. Wagner $V$, Dullaart A, Bock A-K, Zweck $A$. The emerging nanomedicine landscape. Nature Biotechnology, 2006; 24(10): 1211-1217.

83. Hoet PHM, Brüske-Hohlfeld I, Oleg VS. Nanoparticles - know and unknow health risks. Journal of Nanobiotechnology, 2004; 2: 12 doi:10.1186/1477-3155-2-12.

84. Handy RD, Shaw BJ. Toxic effects of nanoparticles and nanomaterials: implications for public health, risk assessment and the public perception of nanotechnology. Health, Risk and Society, 2007; 9(2): 125-144. 